\title{
A VARIAÇÃO DA LATERAL POSVOCÁLICA /L/ NO PORTUGUÊS DO BRASIL
}

\author{
THE VARIATION OF POSTVOCALIC LIQUID/L/IN BRAZILIAN \\ PORTUGUESE
}

\author{
Antonio José de Pinho \\ Mestrando do Programa de Pós-Graduação em Linguística - UFSC \\ Felício Wessling Margotti \\ Programa de Pós-Graduação em Linguística - UFSC
}

\begin{abstract}
Resumo
No português do Brasil, a lateral posvocálica apresenta cinco variantes possíveis, com predomínio da lateral velarizada em certas regiões do sul, ao passo que a variante vocalizada é a predominante nas outras regiões. Tal variação é condicionada tanto por fatores internos (contexto fonológico anterior, posição na palavra etc.) quanto por fatores externos (faixa etária e região geográfica, predominantemente). A presente análise da variação da lateral é feita com base nos dados do projeto ALiB de todas as capitais brasileiras. Com base na fonologia gerativa padrão, busca-se sustentar que, com a vocalização da lateral em final de sílaba, esse fonema deixa de ocupar a coda silábica para fazer parte do núcleo, fazendo com que aumente significativamente o número de sílabas abertas do português do Brasil.
\end{abstract}

Palavras-chave: Variação linguística. Lateral posvocálica. Estrutura silábica. Português Brasileiro. Variação linguística.

\begin{abstract}
In Brazilian Portuguese the postvocalic liquid has five possible variants, with predominance velarized variant in certain southern regions, but the vocalized variant is predominant in other regions. It is also possible deletion. This variation is conditioned by both internal factors (phonological context previous, position in words, etc.) or by external factors (age and geographic region, predominantly). The present lateral variation analysis is based on data from the project ALiB all Brazilian capitals. In the context of standard generative phonology seeks to argue that, with the vocalization of the lateral end of the syllable, the phoneme does not occupy the coda to the core, causing significantly increase the number of open syllables of Portuguese in Brazil.
\end{abstract}

Key-words: Postvocalic liquid. Syllabic structure. Brazilian Portuguese. Linguistic variation.

\section{INTRODUÇÃO}

Pretendemos, neste artigo, estudar a variação do uso da lateral posvocálica no português do Brasil, mais especificamente na região sul, revisando os resultados obtidos por 
outros estudos e também apresentando uma análise de novos dados empíricos. Alguns trabalhos já foram realizados sobre o assunto e verificaram que, em grande parte do território nacional, predomina a variante vocalizada dessa consoante, ou seja, o /1/ em final de sílaba transforma-se em uma semivogal [w], formando, muitas vezes, um ditongo com a vogal do núcleo da sílaba. Sendo assim, palavras como mal e mau (ou vil e viu) confundem-se numa mesma pronúncia: mau e viu. Podemos, portanto, afirmar que ocorre um processo de neutralização entre esses dois fonemas quando esses ocorrem em final de sílaba.

Como podemos observar, há duas principais realizações do fonema na posição de coda. Uma que se denomina de velarizada [ł], mais próxima da lateral plena [1], e uma variante vocalizada $[\mathrm{w}]$.

Dialetalmente falando, a variante velarizada é própria do português de Portugal, ao passo que a variante vocalizada é uma marca bem clara do português falado no Brasil (SÁ, 2006). Entretanto, não podemos dizer que a lateral encontra-se vocalizada em todas as regiões brasileiras. Sendo este um país de dimensões continentais, é de se esperar que nele existam variações dentro do sistema fonológico da língua, como também nos demais componentes da gramática (morfológico, sintático, semântico) e no léxico.

No que diz respeito à realização do /1/ no português do Brasil, estudos apontam para um relativo maior conservadorismo nas regiões mais ao sul. Isso quer dizer que esse fonema se mantém ou se velariza em certas regiões do Rio Grande do Sul e de Santa Catarina, fato que já tinha sido apontado por Câmara Jr., como se observa na citação a seguir:

[...] o contraste entre $/ 1 / \mathrm{e} / \mathrm{w} /$ depois de vogal não deve ir ao ponto de se articular o /1/ depois de vogal exatamente como o /1/ antes de vogal. Salvo no extremo sul do país, esta pronúncia indiferenciada soa anômala, e dá a impressão de haver um ligeiro /i/ depois do /1/ de maneira que uma palavra como cal quase se confunde com cale ou mel com mele (CÂMARA JR., 1977, p. 31).

Depreende-se da observação acima que a articulação dental ou alveolar da lateral em posição de coda silábica é fato comum no sul do país, mas considerada anômala em outras regiões.

De fato, os estudos realizados pelos pesquisadores do Atlas Linguístico-Etnográfico da Região Sul do Brasil - ALERS -, com informantes rurais e de baixa ou nenhuma escolaridade, confirmam a predominância da lateral alveolar ou da correspondente velarizada no item lexical "calção" (ver Mapa 37). A área de predominância do /1/ alveolar ou velarizado (destacada em azul no mapa) ocupa a maior parte do espaço geográfico. A substituição da lateral por um rótico (tepe no Rio Grande do Sul e Santa Catarina e retroflexo no Paraná) está associada ao percurso do tropeiros, em áreas do planalto serrano mais ao e no nordeste paranaense. 
ATLAS LINGÜÍSTICO-ETNOGRÁFICO DA REGIÃO SUL DO BRASIL (ALERS)

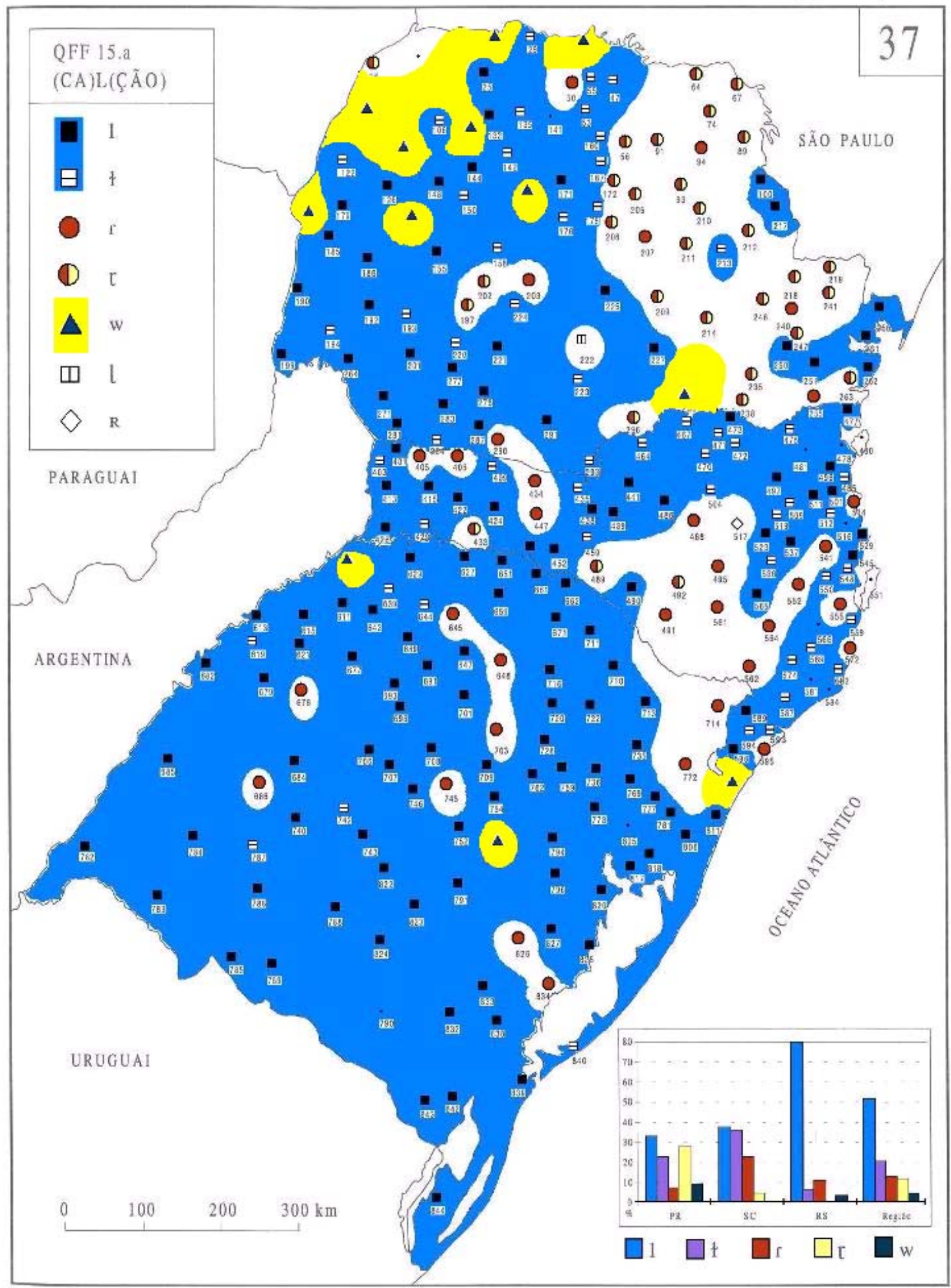

Como se vê, nos dados do ALERS, poucas e esparsas são as ocorrências de vocalização da lateral (destacadas em amarelo), com uma pequena concentração no noroeste do Paraná. 
De certa forma, a preservação da lateral alveolar na região sul do Brasil pode ser associada, em parte, aos contatos linguísticos com a língua espanhola em áreas lindeiras - ver estudos de Espiga (2001, entre outros), relativamente ao português de fronteira dos Campos Neutrais (Chuí e Santa Vitória do Palmar) - e com as línguas de imigrantes, notadamente as línguas italiana e alemã.

Como ficou demonstrado no Mapa 37 do ALERS, a lateral pode ser substituída por um rótico ${ }^{1}$ em certos contextos fonológicos.

Uma outra realização possível da lateral em coda silábica é o seu apagamento após a vogal /u/, fenômeno mais comum, e após a vogal /o/ (mais raro), como podemos observar em palavras como $s u l>s u$ e soldado $>$ sodado. Em tais casos, quando a lateral já vocalizada é apagada, vemos que parece ocorrer um leve alongamento na pronúncia da vogal do núcleo da sílaba, o que poderia ser melhor averiguado em um estudo acústico futuro.

Para entender mais profundamente o fenômeno de vocalização, é necessário, primeiramente retomar os principais resultados obtidos em pesquisas já realizadas sobre o tema, numa busca para compreender quais fatores linguísticos e extralinguísticos entram em jogo na variação da realização do fonema em questão. Assim compreenderse-á melhor quais forças privilegiam uma ou outra forma, quer dizer, a variante velarizada ou a vocalização da lateral.

Num segundo momento, são apresentados novos dados empíricos obtidos pelo Atlas Linguístico do Brasil (ALiB) em todas as capitais, nas quais foram entrevistados 8 informantes estratificados por gênero, idade e escolarização. Além da análise da influência dos fatores internos, pretende-se verificar até que ponto o fator geográfico atua nas realizações da lateral posvocálica, e quais regiões do Brasil privilegiam o apagamento, a vocalização e a velarização da lateral. A apresentação desses dados é de grande importância para o progresso das pesquisas sobre o tema. Os estudos feitos até então forneciam visões pontuais da variação em uma determinada cidade ou região, mas não fornecem uma visão macro, abrangendo todo o território nacional. Com os dados das capitais do AliB, poder-se-á ter uma visão mais ampla desse fenômeno de variação e mudança fonológica. Em conformidade com a metodologia do ALiB, tal parte do presente estudo será abordada dentro da dialetologia pluridimensional (THUN, 2005), a qual incorpora a dimensão vertical ${ }^{2}$ aos estudos geoliguísticos, nos quais predomina a dimensão horizontal (a variação pelo espaço geográfico).

$\mathrm{Na}$ parte seguinte, analisam-se formalmente, dentro do quadro teórico da fonologia gerativa padrão, as regras fonológicas que atuam na transformação da lateral em coda silábica. As regras, que são cíclicas, apresentam-se na ordem cronológica em que surgiram na língua, desde a regra da velarização da lateral, ocorrida no século XIV como veremos -, a seu apagamento completo, em certos contextos.

\footnotetext{
1 À vezes consoante retroflexa, para usar uma outra terminologia.

2 Os fatores sociais condicionantes de processos de variação (escolaridade, sexo, idade etc) tão enfatizados pelos estudos sociolinguísticos.
} 
Por último, faz-se uma reflexão sobre a estrutura da sílaba. Qual será a repercussão da vocalização na configuração silábica portuguesa? Sabemos que o fenômeno de vocalização ocorre juntamente com vários outros que alteram a coda silábica, favorecendo o aumento de sílabas abertas em detrimento das travadas.

\section{UM PERCURSO SOBRE OS ESTUDOS DA LATERAL EM CODA SILÁBICA}

A variação entre a velarização e a vocalização do /1/ em coda silábica é determinada por alguns fatores extralinguísticos (etnia, região, sexo e idade do informante, por exemplo) e linguísticos. Como nos aponta Faraco (2007), o fator idade é bem significativo no estudo desse fenômeno.

Se contrastarmos o português falado hoje na maioria das regiões brasileiras, por pessoas de gerações bem diferentes, vamos observar, por exemplo, que na fala dos mais idosos (digamos a geração de 75 anos), o último som de palavras como mal, papel, lençol é ainda, no mais das vezes, uma consoante lateral, semelhante ao primeiro som de palavras como lama, leite, lado; enquanto na fala de outras gerações o último som é a semivogal $/ \mathrm{w} /$, idêntica ao último som de palavras como mau, céu, vendeu (principalmente entre os falantes da classe média urbana) (FARACO, 2007, p. 12).

O português do Brasil tende, muito em breve, por isso, a substituir a variante velarizada pela vocalizada, já que na fala dos mais novos é a vocalização que predomina. Mas não podemos entender que a vocalização seja um processo novo dentro da história da língua. A transformação do $/ 1 / \mathrm{em} / \mathrm{w} /$ é algo relativamente comum nas línguas, principalmente nas neolatinas. Já, no latim vulgar, pudemos observar a passagem do /1/ para /w/ como é possível atestar nos vocábulos poupar (de palpare) e outro (de alterum). ${ }^{3}$

No francês, segundo nos relata Malmberg (1954), também houve esse processo de velarização e uma posterior vocalização da lateral.

O francês teve antigamente um 1 velarizado que se transformou mais tarde num elemento vocálico (u) em consequência da perda da articulação apical. Este processo é o responsável, por exemplo, pelos plurais franceses de tipo cheval - chevaux. No antigo plural chevalz, o 1 velarizado transformou-se em u, daí um ditongo que terminou por se reduzir a ô (MALMBERG, 1954, p. 81-82).

Esse exemplo citado por Malmberg nos faz ver que esse fenômeno não é algo exclusivo do português, mas algo comum nas línguas, o que talvez reflita uma tendência natural de transformação fonética. Por exemplo, em inglês também há a vocalização da lateral em coda silábica.

No contexto da pesquisa linguística feita no Brasil, há já importantes trabalhos, principalmente elaborados na perspectiva da teoria da variação linguística, que focam a variação da consoante lateral alveolar em posição de final de sílaba (posvocálica). Sem

\footnotetext{
${ }^{3}$ É importante destacar, nestes dois casos, que após a vocalização temos a monotongação, fazendo com que /aw/ transforme-se em [o] e posteriormente em [ow].
} 
querer aqui fazer uma lista exaustiva desses estudos, podemos citar Tasca (1999), Quednau (1993), Quednau et Hahn (2007) Dal Mago (1998), Hora (2006), dentre outros.

No estudo de Dal Mago (1998), foi utilizado o banco de dados do VARSUL ${ }^{4}$, e constatou-se que os fatores extralinguísticos são mais relevantes para o aparecimento da vocalização do que os fatores puramente linguísticos. Por exemplo, os mais escolarizados, ou seja, aqueles que cursaram até o colegial, tiveram uma taxa de vocalização por volta de $50 \%$. Por outro lado, aqueles que possuem somente o primário vocalizaram 30\%. Esses dados indicam que quanto maior é a escolaridade do informante, maior é a vocalização da lateral. O fator escolaridade parece, portanto, um condicionante.

A mesma autora ratificou a afirmação de Faraco (2007), acima citada, de que o fator idade é importante para o fenômeno de variação. Pessoas com mais de 55 anos parecem ser mais conservadoras, mantendo a variante velarizada num percentual de $70 \%$. No outro grupo estão as pessoas com menos de 45 anos, as quais apresentaram apenas $20 \%$ de velarização. No que toca ao fator geográfico, Dal Mago afirma que "o Paraná vocaliza mais que Santa Catarina e esta mais que o Rio Grande do Sul” (1998, p. 37).

Como afirmamos, Dal Mago viu pouca influência de fatores linguísticos determinando a variação, mas esses não podem ser totalmente descartados, pois

Nas palavras em que o /1/ pós-vocálico encontra-se na sílaba tônica há um maior favorecimento à aplicação da regra, ou seja, à vocalização, o mesmo acontece nas palavras que possuem até duas silabas e em palavras em que o contexto precedente do /1/ são vogais /u/, /E/ e /o/ (DAL MAGO, 1998, p. 38).

Outra autora, Quednau (1993), em sua dissertação intitulada A lateral posvocálica no português gaúcho, estudou o mesmo fenômeno linguístico em 4 cidades do Rio Grande do Sul, tendo 7 informantes em cada ponto: Porto Alegre (região metropolitana), Taquara (colonização alemã), Monte Bérico (colonização italiana) e Santana do Livramento (região de fronteira).

\footnotetext{
${ }^{4} \mathrm{O}$ projeto VARSUL (Variação Linguística na Região Sul do Brasil), pensado dentro do contexto metodológico da pesquisa sociolinguística, objetiva a descrição do português falado e escrito em contexto urbano nos três estados brasileiros do sul. O banco de dados do VARSUL é composto por entrevistas gravadas em quatro cidades de cada estado da região sul.
} 
TABELA 1. A presença da variante vocalizada segundo o grupo étnico

\begin{tabular}{|l|lr|c|}
\hline \multicolumn{1}{|c|}{ Fatores } & \multicolumn{2}{|c|}{ Percentual } & Peso \\
\hline Metropolitanos & $\frac{652}{715}$ & $91 \%$ & .95 \\
\hline Alemães & $\frac{73}{363}$ & $20 \%$ & .25 \\
\hline Italianos & $\frac{149}{641}$ & $23 \%$ & .26 \\
\hline Fronteiriços & $\frac{142}{525}$ & $27 \%$ & .31 \\
\hline
\end{tabular}

Fonte: Quednau (1993, p. 44)

Os dados da Tabela 1 acima nos indicam que a vocalização da lateral é praticamente categórica na capital gaúcha, ao passo que é pouco recorrente nas cidades do interior e fronteira. Esses indicadores nos levam a crer, por indução, que a passagem da variante velarizada para a variante vocalizada dá-se da capital para as outras cidades. Isso pode ser explicado pela relação capital $x$ interior. Sabemos que na capital é que está o poder político/econômico. Esses poderes aliam-se ao fato de que na capital é que ocorrem as mudanças de toda sorte de manifestação sociocultural. Como a língua está atrelada à cultura e ao poder, é fácil compreender que a capital saia também inovando no campo linguístico, adotando as formas que serão consideradas pertencentes ao "padrão", ao "bom uso da língua".

Fato semelhante ocorreu no passado, durante a evolução do latim, quando a cidade de Roma era o ponto a partir do qual as inovações linguísticas expandiam-se pelo Império.

Roma era a cabeça política, social e cultural do Império, o grande centro irradiador das inovações linguísticas, que trabalhavam em medida crescente o seu latim vulgar. Ora, essas inovações atingiram em grau diferente as diversas províncias, conforme a distância e a posição de cada uma dentro ou à margem das grandes correntes de comunicação do Império. (MATTOSO CAMARA Jr., 1979, p. 23)

Um acontecimento análogo podemos ver acontecer no português brasileiro atual, no qual a regra de vocalização, na região sul, parece surgir na capital e se propagar para o interior.

Quednau (1993) também verificou a importância do fator idade na evolução do fonema. Os informantes foram divididos em dois grupos, mais novos (de 20 a 40 anos) e mais velhos (de 41 a 55 anos).

TABELA 2. A presença da variante vocalizada segundo a faixa etária

\begin{tabular}{|l|lr|l|}
\hline Fatores & Percentual & Peso \\
\hline $20-40$ anos & $\underline{684}$ & .49 \\
\hline $41-55$ anos & $\frac{332}{892}$ & $37 \%$ & .51 \\
\hline
\end{tabular}

Fonte: Quednau (1993, p. 46) 
Como se observa na Tabela 2, a vocalização cai entre os mais velhos, apresentando apenas $37 \%$ de registros. Por outro lado, entre os mais novos a porcentagem de vocalização sobe para $51 \%$ do total. Ou seja, entre os dois grupos, vemos uma considerável diferença de $14 \%$. Como poderemos observar mais adiante, dados do ALiB corroboram os resultados da pesquisa de Quednau (1993), no que diz respeito aos fatores idade e localização geográfica.

O estudo de Hora (2006) enfoca o comportamento da lateral em João Pessoa, e utiliza como corpus dados do projeto Variação Linguística no Estado da Paraíba (VALPB). Das 3.703 ocorrências da lateral no corpus coletado, o autor constatou que em 3.109 dos casos houve a vocalização, 583 casos de apagamento do fonema, oito casos de aspiração (a lateral realizou-se como [h]) e três casos de velarização. Ficou constatado que a posição do fonema possui certa influência na aparição de uma ou outra variante.

A partir do conjunto dos exemplos apresentados, constatamos que a variante aspirada $[\mathrm{h}]$ ocorre no interior de palavra e o zero fonético ([Ø]), principalmente, no final de palavra (HORA, 2006, p. 35).

No que se refere aos fatores sociais - como idade, sexo e escolaridade -, verificou-se que o fator sexo pouco interfere na variação da lateral, pois enquanto os homens vocalizaram em $83 \%$ dos dados, as mulheres vocalizaram em $85 \%$.

O fator idade revela-se significativo no artigo de Hora (2006), confirmando a afirmações de Faraco (2007) e Quednau (1993) já citadas, uma vez que a taxa de nãovocalização entre o grupo de informantes mais velhos aumenta em relação aos mais novos.

TABELA 3. Atuação do fator "faixa etária"

\begin{tabular}{|l|l|l|l|}
\hline Faixa etária & APL./Total & $\%$ & Peso relativo \\
\hline+ de 49 anos & $939 / 1.213$ & 77 & .37 \\
\hline De 15 a 25 anos & $1.002 / 1.561$ & 87 & .55 \\
\hline De 26 a 49 anos & $168 / 1.323$ & 88 & .58 \\
\hline
\end{tabular}

Fonte: Hora (2006, p. 37)

Como tantos outros estudos sociolinguísticos apontam, quando olhamos a variação na sincronia entre faixas etárias distintas podemos descobrir uma mudança em tempo aparente, se, é claro, os dois grupos sociais apresentarem padrões de fala diferentes, como no caso mostrado pelo estudo de Hora (2006). A inovação ocorre entre os mais jovens enquanto os mais velhos possuem em seus dialetos um padrão de fala conservador. Se, com o passar do tempo, a forma inovadora se expande cada vez mais entre os mais jovens tornando-se categórica, dizemos que houve uma mudança em tempo real. O que no caso da lateral ainda não pode ser afirmado com toda certeza, mas tudo indica que a situação linguística entre Brasil e Portugal tornar-se-á, neste aspecto fonológico, bem polarizada entre a vocalização categórica da consoante no Brasil e a conservação da variante velar em Portugal.

Hora (2006), analisando a influencia dos fatores escolaridade e contexto fonológico precedente, verificou que, se a vogal precedente for anterior (/i/, /e/ e / / /) ou central $(/ a /)$, prevalece a forma vocalizada $/ \mathrm{w} /$, ao passo que, se antes da lateral tivermos uma 
vogal posterior $(/ \mathrm{o} /, / \mathrm{o} / \mathrm{e} / \mathrm{u} /)$, o apagamento será mais constante (culpa $>\mathrm{cu}[\varnothing]$ pa, sul $>$ $\mathrm{su}[\varnothing]$, soldado $>$ so[ø]dado, anzol $>$ anzo[ø]). Em todos os níveis de escolaridade, o apagamento da lateral sempre é mais frequente se precedida por $/ \mathrm{u} /$, que formaria $o$ ditongo [uw] se não houvesse a crase, uma vez que a "realização do tipo [uw] não é aceitável na nossa língua, isto porque geraria um ditongo mal-formado" (HORA, 2006, p. 40).

O cruzamento entre escolaridade e contexto fonológico precedente mostra que, seja qual for a vogal a anteceder, o apagamento cresce entre menos escolarizados, enquanto os mais escolarizados (com mais de 11 anos de escolarização) tendem a vocalizar, inclusive preservando o ditongo [uw] em $47 \%$ dos casos (HORA, 2006).

Num estudo sobre o português de base açoriana falado no litoral de Santa Catarina, Furlan (1989) mostra que pode ocorrer paragoge em palavras terminadas por $/ 1 /$, fato que ocorre por fatores de ordem articulatória. Palavras como carnaval e mal tornam-se carnavali e mali, respectivamente. $\mathrm{O}$ autor lembra, entretanto, que essa característica dialetal, herdada pelos colonos açoriados vindos em meados do século XVIII, só é encontrada na fala de pessoas muito idosas.

[...] no açoriano-catarinense, os falantes de faixa etária alta e de pouca escolarização apresentam, ainda viva, a tendência a apoiar com [i] ou [e] os oxítonos terminados em $1, \mathrm{r}, \mathrm{s}, \mathrm{z}$, fenômeno que ocorre sobretudo ante pausa; ex.: sal ['sale], mar ['mare], faz ['faze].

No português europeu, o apoio é traço amplamente difundido em todos os níveis sociolingüísticos, mas só após líquidas; Brasil $\left[\mathrm{br}^{\mathrm{al}} \mathrm{sil}^{\mathrm{e}}\right]$, ir $\left[{ }^{\mathrm{i}} \mathrm{ir}^{\mathrm{e}}\right]$. Quanto aos Açores, o registro cinge-se à líquida lateral; ex.: terrível [te'rive $1^{\mathrm{e}}{ }^{\mathrm{e}}$ ] (Terc.) (FURLAN, 1989, p. 15-16).

Não deixa de ser interessante o aparecimento de uma vogal paragógica nessas variedades dialetais do português. Porque o acréscimo de um [e] ou [i] ocorre justamente pelo fato de existir uma tendência românica a privilegiar a estrutura silábica consoante mais vogal ou ditongo (CV, CVV) (FURLAN, 1989). Além disso, a paragoge também transforma palavras oxítonas em paroxítonas, o padrão acentual mais comum em português. Sabemos que palavras terminadas em $/ \mathrm{r} / \mathrm{e} / \mathrm{l} /$ geralmente são oxítonas, segundo nos afirma Mattoso Câmara (2008 [1970]). Mas, quando é acrescentada uma vogal anterior ao seu fim, elas assumem uma nova configuração acentual paroxítona, a mais frequente nas palavras portuguesas. ${ }^{5}$

Por último, temos o estudo de Sá (2006) que fez uma interessante comparação do comportamento da lateral entre o espanhol e o português, que são línguas estreitamente vinculadas por suas histórias de origem comum no latim vulgar.

A variação da lateral em espanhol é bem diferente da que vimos ocorrer em português. $\mathrm{Na}$ língua portuguesa, estruturalmente falando, é o contexto anterior que mais influencia na vocalização ou apagamento do fonema. Por outro lado, em espanhol o contexto

\footnotetext{
${ }^{5} \mathrm{O}$ grande número de palavras de origem indígena no português brasileiro, principalmente oriundas do tupi, fez com que ele passasse a ter um número maior de oxítonos do que no português de Portugal (MATTOSO CAMARA Jr., 2008 [1970], p. 65).
} 
seguinte é o mais determinante. Se após a lateral temos um fonema alveolar a lateral se realizará como alveolar. O que demonstra existir constantemente um processo de assimilação regressiva do ponto de articulação. Em espanhol a lateral também pode se realizar como velar, mas isso depende do contexto à direita do fonema. De qualquer forma o que deve aqui ser destacado é que o contexto fonológico na variação da lateral em coda é bem mais significativo em espanhol que em português.

\section{A VARIAÇÃO DA LATERAL NAS CAPITAIS}

Após termos visto os principais dados de alguns estudos realizados sobre a variação da lateral em final de sílaba, passemos agora à análise de novos dados obtidos pelo principal estudo dialetológico feito sobre o português brasileiro, o Atlas Linguístico do Brasil. Iniciado em 1996, encontrando-se ainda em andamento, o ALiB é um projeto de abrangência nacional, no qual estão envolvidos pesquisadores de várias universidades brasileiras, sob a direção geral de Suzana Alice Cardoso.

No total, objetiva-se a realização de 1100 entrevistas em 250 localidades distribuídas por todo o país. São quatro informantes entrevistados por ponto (estratificados por idade e gênero), sendo que, nas capitais, são oito, controlando-se também o fator escolaridade. As entrevistas são feitas por meio de questionários, em que as perguntas foram elaboradas com o objetivo de registrar a variação linguística do nível fonéticofonológico ao pragmático-discursivo. Os questionários aplicados nas entrevistas são fonético-fonológico, semântico-lexical, morfossintático, pragmático e um com temas para discursos semidirigidos. Desses questionários selecionamos algumas questões do fonético-fonológico, que tinham como objetivo registrar a variação justamente na lateral alveolar.

Da amostra de 1100 entrevistas, selecionamos todas as 200 entrevistas realizadas nas capitais. Como já foi colocado, são oito entrevistados por capital, distribuídas como indica a Tabela 4.

TABELA 4. Perfil dos informantes

\begin{tabular}{|c|l|l|l|}
\hline Informante & Sexo & Idade & Escolaridade \\
\hline $\mathbf{1}$ & Homem & 18 a 30 anos & até $7^{\mathrm{a}}$ série \\
\hline $\mathbf{2}$ & Mulher & 18 a 30 anos & até $7^{\mathrm{a}}$ série \\
\hline $\mathbf{3}$ & Homem & 50 a 65 anos & até $7^{\mathrm{a}}$ série \\
\hline $\mathbf{4}$ & Mulher & 50 a 65 anos & até $7^{\mathrm{a}}$ série \\
\hline $\mathbf{5}$ & Homem & 18 a 30 anos & ensino superior \\
\hline $\mathbf{6}$ & Mulher & 18 a 30 anos & ensino superior \\
\hline $\mathbf{7}$ & Homem & 50 a 65 anos & ensino superior \\
\hline $\mathbf{8}$ & Mulher & 50 a 65 anos & ensino superior \\
\hline
\end{tabular}

Dessa forma, como é próprio de uma pesquisa feita dentro da perspectiva da geolinguística pluridimensional, além da variação diatópica, investiga-se também a variação diastrática, como nos estudos sociolinguísticos, controlando-se, nesse caso, as dimensões sexo, idade e escolaridade. 
Os itens lexicais do questionário fonético-fonológico selecionados para a amostra foram:

$\begin{array}{lll}\text { [pól]vora } & {[\text { al]moço }} & \text { [sal] } \\ {[\text { mel] }} & {[\text { sol] }} & \text { a[zul] } \\ \text { Bra[sil] } & \text { [sol]dado } & \text { [cal]ção } \\ {[\text { al]ta }} & \text { a[nel] } & \end{array}$

$\mathrm{Na}$ Tabela 5, podemos ver um resumo dos dados obtidos nas 200 entrevistas. A vocalização predomina no português brasileiro, com um total de quase $88 \%$, dados que confirmam as constatações de estudos anteriores.

TABELA 5. Resumo das ocorrências da /1/ em coda silábica capitais brasileiras

\begin{tabular}{|l|l|c|c|c|c|c|c|c|}
\hline & & 1 & $\mathbf{1}$ & W & $\boldsymbol{\emptyset}$ & Rótico & RP & Totais \\
\hline Norte & Macapá & & & 83 & 1 & & 4 & 88 \\
\hline & Boa Vista & & & 85 & 3 & & & 88 \\
\hline & Manaus & & & 82 & 5 & & 1 & 88 \\
\hline & Belém & & & 80 & 8 & & & 88 \\
\hline & Rio Branco & & & 83 & 5 & & & 88 \\
\hline & Porto Velho & & & 83 & 2 & & 3 & 88 \\
\hline Nordeste & São Luís & & & 80 & & & 8 & 88 \\
\hline & Teresina & & & 76 & 12 & & & 88 \\
\hline & Fortaleza & & & 72 & 11 & & 5 & 88 \\
\hline & Natal & & & 77 & 9 & & 2 & 88 \\
\hline & João Pessoa & & & 74 & 11 & & 3 & 88 \\
\hline & Recife & & & 65 & 19 & & 4 & 88 \\
\hline & Maceió & & & 67 & 19 & 2 & & 88 \\
\hline & Aracaju & & & 76 & 9 & & 3 & 88 \\
\hline & Salvador & & & 70 & 14 & & 4 & 88 \\
\hline & Cuiabá & & & 72 & 4 & 7 & 5 & 88 \\
\hline & Campo Grande & & 1 & 66 & 3 & 6 & 12 & 88 \\
\hline & Goiania & 1 & & 78 & 3 & & 6 & 88 \\
\hline & Belo Horizonte & & & 83 & 3 & & 2 & 88 \\
\hline & São Paulo & & & 79 & 5 & 1 & 3 & 88 \\
\hline & Vitória & & & 81 & 1 & 1 & 5 & 88 \\
\hline & Rio de Janeiro & & & 82 & 1 & & 5 & 88 \\
\hline & Curitiba & & & 83 & 4 & 1 & & 88 \\
\hline & Florianópolis & & & 84 & 2 & 1 & 1 & 88 \\
\hline & Porto Alegre & 8 & 8 & 71 & 1 & & & 88 \\
\hline & Totais & 9 & 9 & 1932 & 155 & 19 & 76 & 2200 \\
\hline & Percentuais & $\mathbf{0 , 4 1 \%}$ & $\mathbf{0 , 4 1 \%}$ & $\mathbf{8 7 , 8 1 \%}$ & $\mathbf{7 , 0 4 \%}$ & $\mathbf{0 , 8 7 \%}$ & $\mathbf{3 , 4 5 \%}$ & $100 \%$ \\
\hline & & & & & &
\end{tabular}

Outra constatação importante é com relação à preservação da lateral relativamente ao processo de vocalização. Vimos que quanto mais ao sul, menor é a ocorrência da vocalização. Os dados da Tabela 5 confirmam isso, ao sinalizar que na região sul só houve registro da lateral plena [1] e da variante velarizada [1] no Rio Grande do Sul, totalizando oito registros de cada variante. 
Porém, há uma informação relevante sobre a preservação da lateral no sul. A variante não vocalizada está presente apenas na fala dos informantes mais velhos da capital gaúcha. Isso indica que realmente estamos vendo um processo de mudança na estrutura fonológica do português brasileiro - já em conclusão -, em que a língua deixa de ter a presença da lateral alveolar em posição de coda silábica. Fenômeno este que está provocando uma reestruturação da sílaba. Os processos de mudança - vocalização e apagamento de consoantes em posição de coda - tem favorecido as estruturas $\mathrm{CV}$ e CVV, desfavorecendo a estrutura CVC.

Considerando o fator geográfico, vemos que os róticos aparecem como variantes da lateral principalmente na região centro-oeste. Essa variante da lateral é, possivelmente, um traço dos dialetos da região, mas tal afirmação precisa dos dados do ALiB das cidades de interior para ser confirmada.

O apagamento da lateral, por sua vez, é maior na região nordeste (com pouco mais de $13 \%$ de apagamento) e norte, sendo que nesta região decresce o índice de apagamento da lateral. Isso poderá ser melhor visto no Gráfico 1.

GRÁFICO 1. Apagamento da lateral nas regiões brasileiras (em porcentagem)

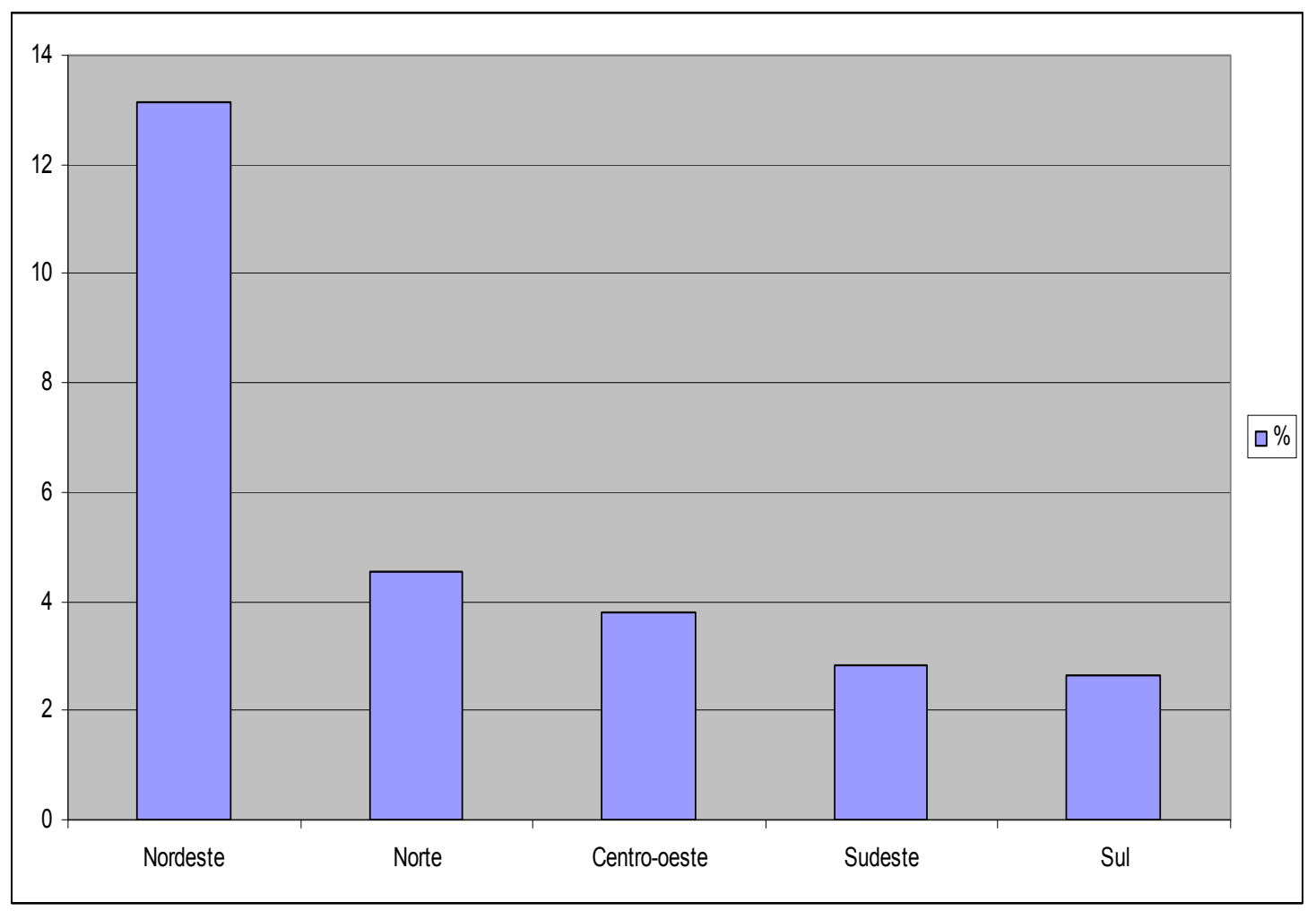

Até agora temos visto a interferência de fatores externos no processo de variação/mudança, mas os fatores internos também são fundamentais para a compreensão do processo em estudo. Nos Gráficos 2 e 3, podemos ver a relevância do contexto fonológico anterior. $\mathrm{O}$ apagamento da lateral chega a quase $60 \%$ na palavra azul e a pouco menos de $20 \%$ no vocábulo pólvora. Também há apagamento, porém bem inferior, na palavra soldado, a qual passa a ser pronunciada, em alguns casos, como sodado. 
GRÁFICO 2. Variantes da lateral por item lexical

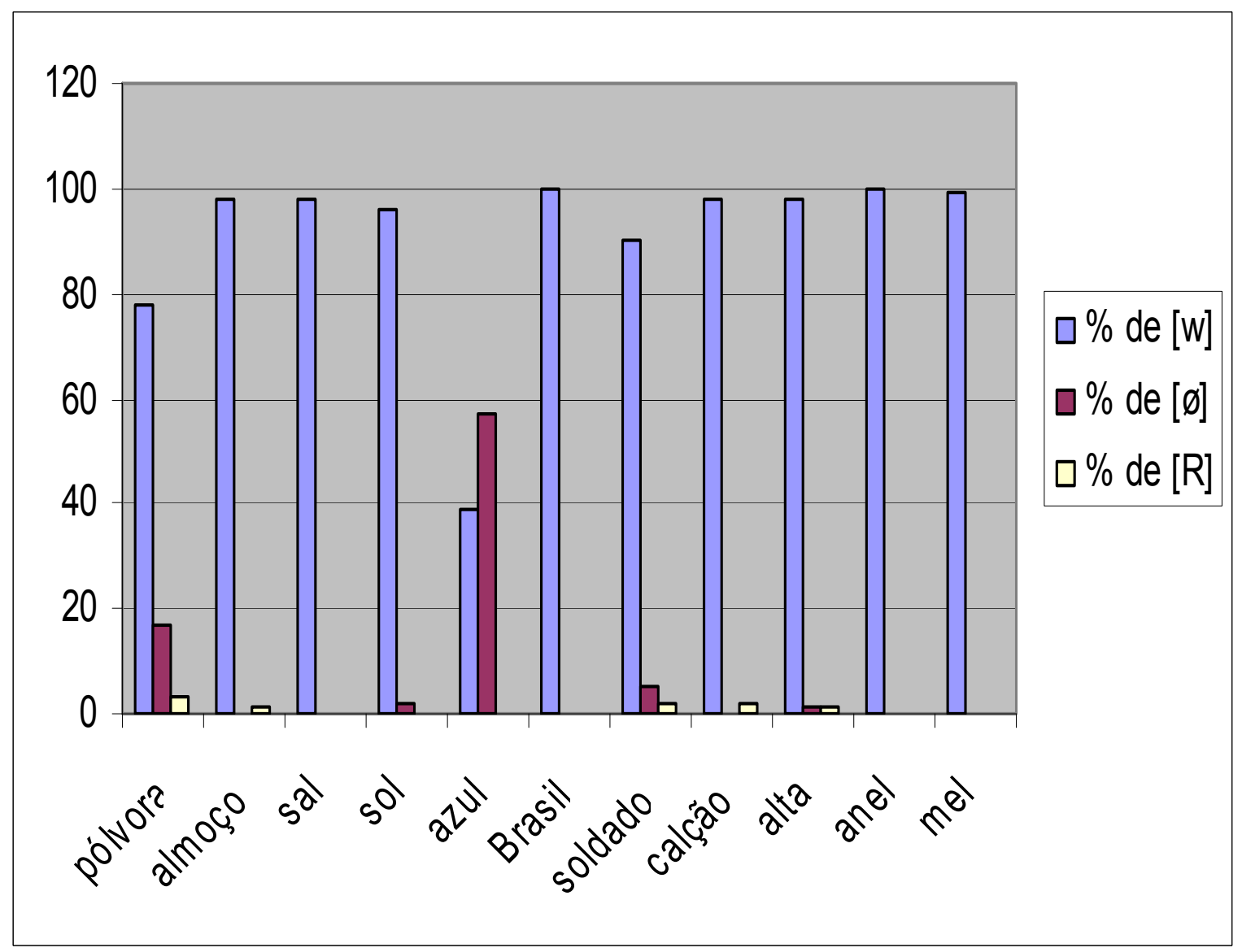

GRÁFICO 3. Realização da lateral e o contexto precedente

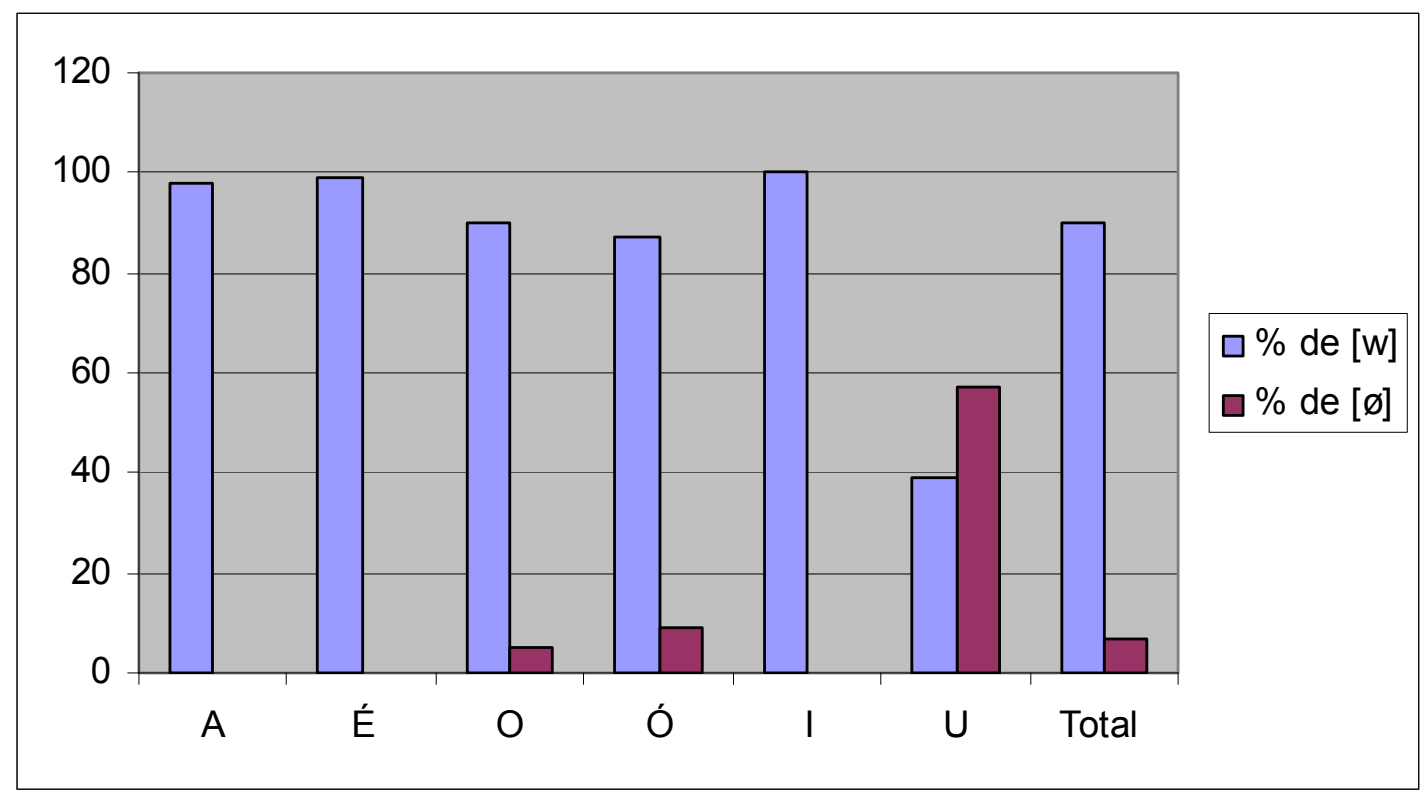


Dessa forma, podemos constatar, através do Gráfico 2, que as vogais [o], [o] e [u], principalmente, constituem o contexto precedente que favorece o apagamento da lateral. Sendo assim, claramente se vê que as vogais posteriores são aquelas que, por motivos estruturais, fazem a lateral passar por seu último estágio evolutivo.

A lateral é apagada em tais contextos pela maior similaridade articulatória entre a variante vocalizada da lateral e a vogal do núcleo da sílaba. Quando temos o apagamento podemos dizer que existe um processo de assimilação total progressiva do fonema da coda. $\mathrm{O}$ que resulta numa crase.

Logo se compreende porque os índices de apagamento são maiores quando a lateral vocalizada é antecedida pela vogal /u/. Há entre esses dois fonemas uma completa similaridade articulatória, o que favorece fortemente a "fusão" dos dois segmentos sonoros em um só. O mesmo não ocorre com as vogais anteriores, que se diferenciam do ponto de vista articulatório, da lateral vocalizada. Essa maior diferença articulatória acaba por desfavorecer o apagamento da coda silábica.

Voltando à variação diatópica, não podemos deixar de constatar uma espécie de polarização entre as regiões sul e nordeste. Claro que a vocalização é frequente em ambas as regiões. Mas, enquanto o sul é relativamente conversador (há a preservação da lateral sem vocalizar e baixos índices de apagamento), a região nordeste, pelo contrário, inova ao liderar como a área com mais elevadas porcentagens de apagamento e nenhum registro das variantes [1] e [ł].

Tal polarização também pode ser observada nos outros componentes da gramática, assim como também em outros aspectos da própria estrutura fonológica. Por exemplo, o aspecto que mais se destaca é a neutralização das vogais médias em posição pré-tônica, tão característica de certos dialetos nordestinos. Sabemos que as vogais abertas $[\varepsilon]$ e [o] normalmente só ocorrem em posição tônica. $\mathrm{O}$ fato é que, em certas áreas do nordeste, elas ocorrem em posição pré-tônica. Quando isso acontece, temos um fenômeno de neutralização entre as vogais médias.

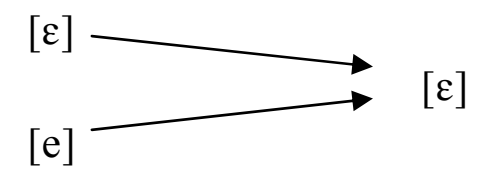

Exemplo: menino[me'ninu] $>\left[\mathrm{m \varepsilon}^{\prime} \operatorname{nin} u\right]$.

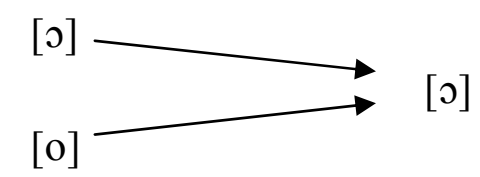

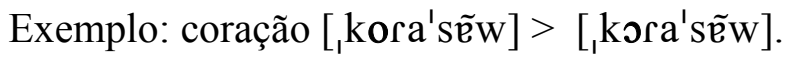

No campo morfológico também as pesquisas têm apontado para uma sensível diferenciação entre o português falado do nordeste e o do sul. Vejamos o caso do imperativo, amplamente estudado por Scherre (2004) e Silva Alves (2009). Scherre 
constata que "o uso de imperativo associado ao indicativo chega a um percentual médio de $90 \%$, em amostras de fala da região Nordeste, este uso chega a um percentual médio de apenas $30 \%$ " (2004, p. 232). Isso significa que, na região sul, temos as formas imperativas do tipo "menino, corre pra cara!", nas quais a morfologia do imperativo vem do indicativo, "ele corre". Ou contrário disso, o português do nordeste expressa o imperativo da forma verbal vinda do subjuntivo:

\section{Corra pra casa, menino! $<$ Quero que ele corra.}

Esse fato morfossintático tende a reforçar a hipótese de que há uma grande diferenciação entre o português do sul e o do nordeste nos vários níveis gramaticais, do fonético-fonológico (o foco do presente trabalho) ao nível semântico-lexical. Evidentemente, só a análise do restante dos dados do ALiB possibilitará uma maior certeza sobre isso. Por outro lado, tudo caminha para que essa constatação de uma grande diferenciação linguística entre sul/sudeste e norte/nordeste seja confirmada, se tomarmos como base os estudos pontuais e observações informais da fala dessas regiões.

\section{A REGRA DE VOCALIZAÇÃO DA LATERAL}

Do pondo de vista diacrônico, a transformação do /1/ em /u/ passa por um estágio intermediário, como se afirmou anteriormente, em que o fonema apresenta-se velarizado. Tal processo ocorre com um levantamento do dorso posterior da língua rumo ao palato mole. Posteriormente perde-se o contato da língua com os alvéolos e tem-se o arredondamento dos lábios, ocorrendo a vocalização.

Mattoso Câmara (2008 [1970]) descreve com grande precisão a mudança na articulação desse fonema em sua clássica obra Estrutura da Língua Portuguesa:

[...] além do movimento da ponta da língua junto dos dentes, há um levantamento do dorso posterior da língua para junto do véu palatino, dando o que provavelmente os gramáticos latinos chamavam o 1 pinguis ou "gordo". Daí decorre uma mutação, que em lingüística diacrônica se chama "vocalização" da consoante: cessa a elevação da ponta da língua junto aos dentes, a elevação posterior do dorso não chega a interromper a corrente de ar, e há um concomitante leve arredondamento dos lábios. O resultado é um /u/ assilábico, e mal torna-se homônimo de mau, vil de viu e assim por diante. Em outros termos, desaparece da língua o /1/ posvocálico [...]. (MATTOSO CÂMARA Jr., 2008 [1970], p. 51)

Mas aqui fica a pergunta: em que período da história da língua portuguesa teria ocorrido a velarização da lateral?

Leite de Vasconcelos (1888-1889), numa breve nota publicada no primeiro volume da Revista Lusitana, possivelmente o primeiro estudo sobre a evolução do /1/ em coda silábica no português medieval, nos relata que, nos séculos XIV e XV, há inúmeros registros do uso do $l$ dobrado em final de sílaba, ao contrário do que ocorria antes. Há palavras grafadas como tall, quall, reall, sinall etc. Como sabemos, a língua escrita da época (o português arcaico) estava bem mais próxima da fala do que em períodos 
posteriores, pois ainda não se tinha estabelecido uma norma gramatical e ortográfica oficial. Por isso, Leite de Vasconcelos levanta uma hipótese bem plausível, segundo a qual a velarização ocorreu nesse período (século XIV), em Portugal, e foi representada na ortografia por $l l$, pronúncia que permaneceu nos séculos posteriores.

Desta forma, o português trazido, do século XVI em diante pelos colonizadores lusitanos já possuía a forma velarizada. A vocalização do fonema é marca própria do português do Brasil, e possivelmente uma mudança não tão antiga assim, visto que ainda há falantes mais idosos que ainda apresentam a variante velarizada.

Apresentamos abaixo, portanto, o esquema com a síntese evolutiva desse fonema no tempo:

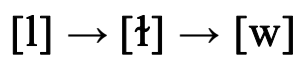

Numa abordagem gerativa, a lateral é caracterizada pelos seguintes traços: - vocálico, + consoante, + contínuo, - alto, - posterior, + anterior, + coronal, + sonoro. No processo de velarização, os traços - alto e - posterior passam a ser positivos.

$$
\left[\begin{array}{l}
\text { - vocálico } \\
+ \text { consoante } \\
+ \text { contínuo } \\
\text { - alto } \\
\text { - posterior } \\
+ \text { anterior } \\
+ \text { coronal } \\
+ \text { sonoro }
\end{array}\right] \longrightarrow\left[\begin{array}{l}
\text { - vocálico } \\
+ \text { consoante } \\
+ \text { contínuo } \\
+ \text { alto } \\
+ \text { posterior } \\
- \text { anterior } \\
+ \text { coronal } \\
+ \text { sonoro }
\end{array}\right] / \longrightarrow
$$

Substituindo a matriz de traços binários pelos símbolos do alfabeto fonético internacional, temos a seguinte regra:

$$
[1] \rightarrow[1] / \ldots
$$

Leia-se: a lateral alveolar torna-se velarizada no contexto de final de sílaba.

Apresentando, agora, a regra de vocalização da lateral velarizada, temos o seguinte esquema: 


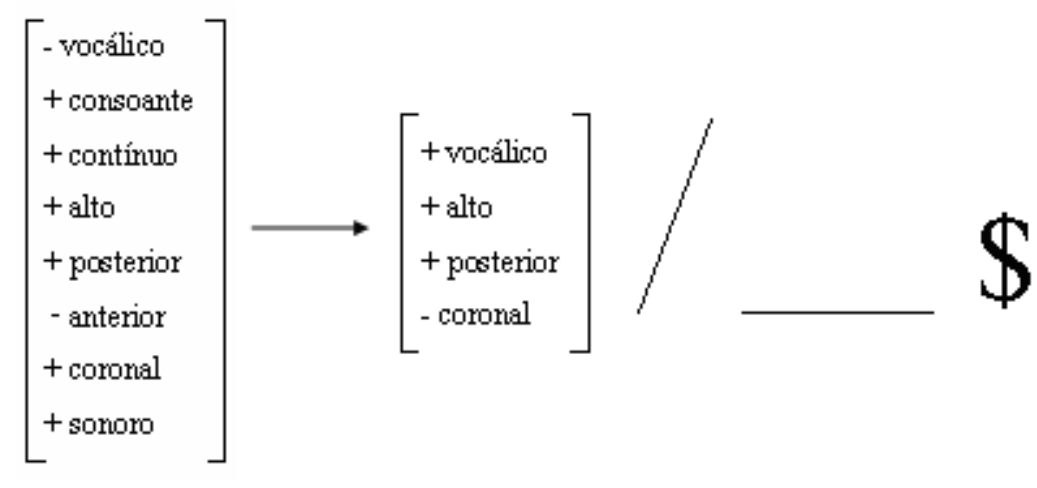

Novamente, como foi feito anteriormente na regra de velarização, substituindo os traços fonológicos pelos símbolos do alfabeto fonético, temos:

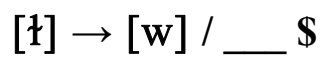

Leia-se: a lateral velarizada torna-se uma semivogal no contexto de final de sílaba.

A aplicação dessas regras é, pois, cíclica ${ }^{6}$ : aplica-se uma após a outra. Mas também não devemos esquecer que, como nos aponta Hora (2006), também é possível a aplicação de uma regra de apagamento da lateral quando vocalizada e precedida por vogais posteriores, principalmente a vogal /u/ no português brasileiro padrão da atualidade.

$$
[\mathrm{w}] \rightarrow[\mathbf{0}] /[\mathrm{u}]
$$

\section{A MUdANÇA NA ESTRUTURA SILÁBICA}

A posição de final de sílaba sofreu profundas alterações ao longo tempo que separa o latim clássico do português atual, ao passo que os fonemas de início de palavra geralmente sobreviveram sem profundas mudanças. A coda silábica latina era bem mais rica do que a portuguesa, pois admitia uma gama bem mais ampla de fonemas consonantais. Em latim clássico, "com exceção de $f, g, h, p$ e $q$, todas as demais consoantes podiam figurar como finais de palavras latinas" (COUTINHO, 1974, p. 116). Havia ainda a possibilidade de uma coda ramificada, ou seja, com dois fonemas consonantais, como nos vocábulos pax /'paks/ e rex/'réks/, onde o último som pronunciava-se como uma oclusiva velar surda seguida por uma fricativa alveolar, também surda.

\footnotetext{
${ }^{6}$ Ou regra telescópica, segundo Tasca (1999).
} 


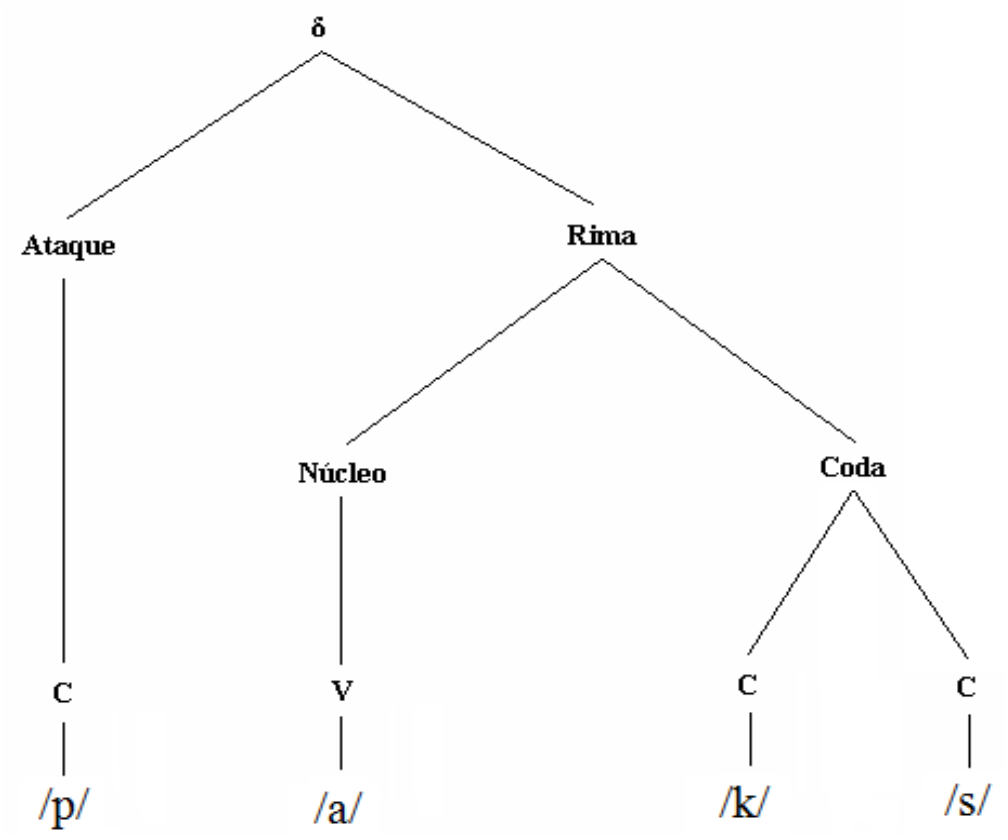

Houve, entretanto, uma grande redução no número de fonemas que poderiam ocupar essa posição na silaba, restando no fim, em português, somente 4 fonemas consonantais em posição de final de sílaba: /1/,/r/, /s/ e /N/.

Mesmo esses 4 fonemas, muitas vezes, acabam sofrendo apócope, em vários dialetos. $\mathrm{O}$ $/ \mathrm{r} /$ em final de palavra cai comumente, principalmente em formas verbais no infinitivo. $\mathrm{O}$ segmento nasal /N/, que foneticamente se realiza como um ditongo nasalizado [ẽj] na língua padrão, em final de palavra, também é apagado em muitos casos, geralmente em níveis menos formais de comunicação.

(1) $/ \mathrm{r} / \rightarrow$ falar $>$ falá, correr $>$ corrê, calor $>$ calô, doutor $>$ doutô.

(2) $/ \mathrm{N} / \rightarrow$ homem $>$ home, abdômen $>$ abdome, margem $>$ marge.

Notemos que, nos dois casos, ou seja, tanto na queda do arquifonema nasal quanto na do tepe na posição de coda, a mudança ocorre no sentido do favorecimento da aparição cada vez maior de sílabas abertas na sua margem direita. Com a vocalização da lateral, dá-se o mesmo. A troca da variante velarizada do fonema pela vogal aumenta de forma expressiva o número de ditongos no português, os quais já são abundantes, e, ao mesmo tempo, também amplia consideravelmente a porcentagem de sílabas que não são travadas por consoantes à direita.

O padrão silábico das sílabas atingidas pela vocalização, portanto, altera-se. A posição de coda silábica, antes ocupada pela lateral, agora encontra-se vazia. Além disso, o núcleo vocálico, antes geralmente ocupado por uma vogal, agora recebe a semivogal $[w]$, tornando-se ramificado, como se demonstra a seguir. 


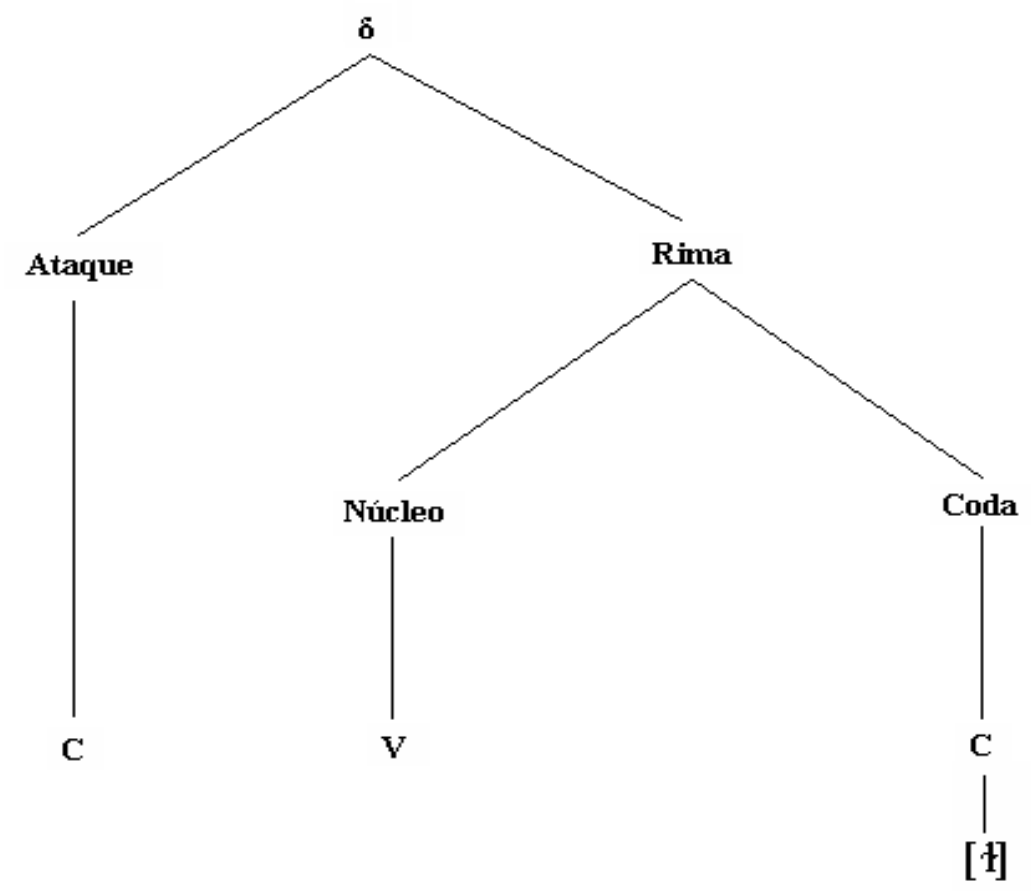

Num segundo momento, a sílaba assume o padrão CVV (sílaba simples), deixando de ser travada.

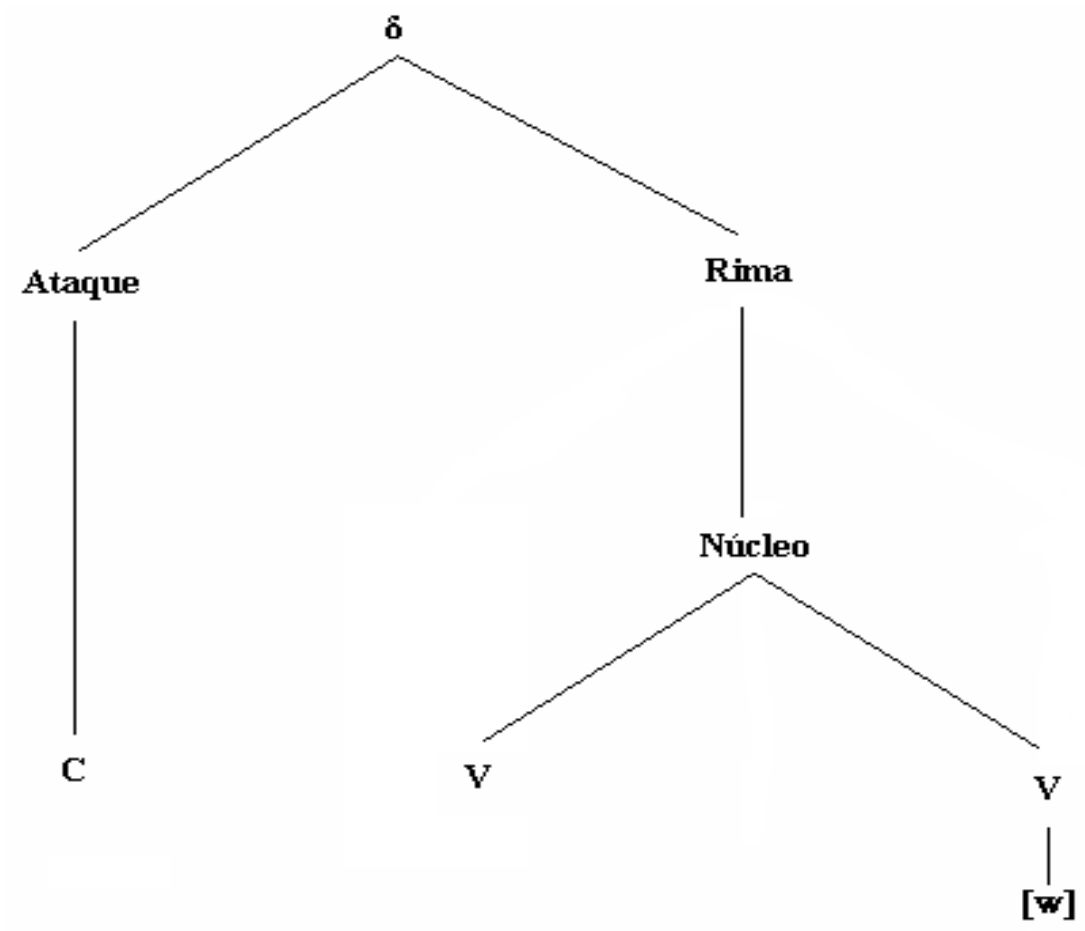

Nas árvores acima, representam-se três momentos da língua em mudança, com seus respectivos padrões silábicos. 


\section{CONCLUSÕES}

Nesse artigo, não tivemos a intenção de esgotar o assunto, mas refletir sobre algumas questões relacionadas à variação linguística nos usos da lateral alveolar /1/ em final de sílaba. No português do Brasil, tal fonema apresenta, portanto, uma variante velarizada [ł] ao lado da variante vocalizada [w], podendo ocorrer, inclusive, o apagamento desse segmento sonoro, assim como substituições por um rótico, embora com pouca frequência entre os falantes das capitais.

A variação é condicionada por alguns fatores linguísticos (do próprio sistema gramatical) e também extralinguísticos (localização geográfica, etnia, sexo, idade, escolarização etc.).

No plano linguístico, observou-se que a vocalização do /1/ é algo comum em outras línguas, inclusive entre o grupo das neolatinas. No francês, por exemplo, esse fenômeno já ocorreu em séculos passados, tendo repercussões na morfologia flexional da língua. Na própria história do português temos casos de vocalização, como no caso do vocábulo outro, que veio latino alter justamente pela transformação do $[l]$ em $[u]$. Verificou-se que é o contexto fonológico antecedente que mais se mostra relevante nesse processo de variação entre a variante vocalizada e o seu apagamento. Ela tende a ser preservada se antecedida por vogais anteriores ou pela central /a/. Por outro lado, se antecedida por posteriores altas, a tendência é o apagamento, principalmente diante de $/ \mathrm{u} /$.

Agora, no plano extralinguístico, são os fatores de ordem social e geográfica ${ }^{7}$ que mais condicionam a variação entre a forma velarizada [ł] e a vocalizada [w]: esta prevalece no português do Brasil, ao passo que aquela no português de Portugal. Dentro dos dialetos brasileiros, há uma tendência de preservação da variante velarizada [ł] na região sul, principalmente no Rio Grande do Sul, conforme atestam os dados do ALERS (Mapa 37). Mas estudos revelaram que em Porto Alegre privilegia-se a vocalização, ao contrário de regiões mais interioranas, que nesse aspecto são mais conservadoras. Dessa forma, tudo indica que a vocalização avança no território gaúcho da capital para o interior, e se expande entre as novas gerações, apontando para uma mudança linguística favorável à forma inovadora.

Os dados das capitais fornecidos pelo ALiB confirmam os estudos anteriores e ampliam o entendimento da variação diatópica do fonema. Temos um maior conservadorismo ao sul e inovação no nordeste, que apresenta significativos índices de apagamento da lateral.

Ainda na análise dos dados do ALiB, podemos observar também indícios de uma mudança em tempo aparente, na medida em que a lateral velarizada ocorreu na fala dos informantes mais velhos, em Porto Alegre, ao passo que, entre os mais novos, predomina a vocalização.

Estruturalmente falando, o fenômeno de vocalização altera a configuração da sílaba portuguesa, ampliando, por um lado, o número de ocorrências de ditongos e, por outro, reduzindo as sílabas travadas, ou seja, aquelas terminadas por segmentos consonantais.

\footnotetext{
${ }^{7}$ Há uma maior influência do fator geográfico na variação da lateral em coda silábica.
} 
Além da vocalização e apagamento da lateral, vê-se que outros processos têm atuado sobre a coda silábica, como a queda dos fonemas $/ \mathrm{s} /, / \mathrm{r} /$, e $/ \mathrm{N} /$, principalmente em final de palavra. Tudo isso indica que a língua caminha para uma estrutura silábica cada vez mais $\mathrm{CV}$.

\section{REFERÊNCIAS}

ATLAS LINGUÍSTICO-ETNOGRÁFICO DA REGIÃO SUL DO BRASIL (ALERS). Volume 2: Cartas Fonéticas e Cartas Morfossintáticas. ALTENHOFEN, Cléo V.; KLASSMANN, Mário Silfredo; KOCH, Walter (orgs.) et al. Porto Alegre: Ed. da UFRGS; Florianópolis: Ed. da UFSC; Curitiba: Ed. da UFPR, 2002.

ATLAS LINGUÍSTICO DO BRASIL (ALiB). Questionários. Londrina: Universidade Estadual de Londrina, 2001.

CÂMARA JR., J. M. Manual de expressão oral e escrita. Petrópolis: Vozes, 1977. Dicionário de lingüística e gramática. 7 ed. Petrópolis: Vozes, 1977 b. 1979. História e estrutura da língua portuguesa. 3 ed. Rio de Janeiro: Padrão,

. Estrutura da língua portuguesa. 41 ed. Petrópolis: Vozes, 2008 [1970].

COUTINHO, Ismael da Lima. Pontos de gramática histórica. 6 ed. Rio de Janeiro: Livraria Acadêmica, 1974 [1938].

CRISTÓFARO SILVA, Thais. Fonética e fonologia do português: roteiro de estudos e guia de exercícios. 9 ed. São Paulo: Contexto, 2007.

DAL MAGO, Diane. O comportamento do /1/ pós-vocálico no sul do país. Working Papers em Linguística, n. 1, 1998. p. 31-44.

ESPIGA, J. W. R. O português do Campos Neutrais: um estudo sócio-linguístico da lateral posvocálica nos dialetos fronteiriços do Chuí e Santa Vitória do Palmar. Porto Alegre: PUCRS, 2001. Tese de doutorado.

FARACO, Carlos Alberto. Linguística histórica: uma introdução ao estudo da história das línguas. São Paulo: Parábola, 2007.

FURLAN, Osvaldo A.. Influência açoriana no português do Brasil em Santa Catarina. INSVLANA, vol. XLV, 1989, p. 5-32.

HORA, Dermeval da. Variação da lateral /1/: correlação entre restrições sociais estruturais. SCRIPTA, Belo Horizonte, v. 9, n. 18, p. 29-44, $1^{\text {o }}$ semestre. 2006.

LEITE DE VASCONCELOS, José. Para a história do L. Revista Lusitana, v. 1, 18881889 , p. 64-65. 
MALMBERG, Bertil. A fonética. Lisboa: Livros do Brasil, 1954.

MARGOTTI, Felício W.; PINHO, Antonio José de; SOUZA, Olívia P. de. A lateral alveolar em coda silábica nas capitais brasileiras: um estudo geolinguísticos. In: $9^{\circ}$ Encontro do CELSUL: caderno de programação e resumos. Palhoça: Editora da Unisul, 2010.

QUEDNAU, Laura Rosane. A lateral posvocálica no sul do Brasil: análise variacionista e representação não-linear. Porto Alegre: UFRGS, 1993. Dissertação de mestrado.

HAHN, Laura Helena. A lateral posvocálica no português de Londrina: análise variacionista e estrutura silábica. Letras de Hoje, v. 42, n. 3, p. 1000-113, setembro, 2007.

SÁ, Edmilson José de. O uso variável da lateral /1/ posvocálica em posição de coda em português e espanhol. Revista Virtual de Estudos da Linguagem - ReVEL. Ano 4, n. 7, agosto de 2006.

SCHERRE, Maria M. P. Norma e uso: o imperativo no português brasileiro. In: DIETRICH, WOLF; NOLL, Volker. (orgs.) O português do Brasil: perspectivas da pesquisa atual. Madrid/Frankfurt am Main: Iberoamericana/Vervuet, 2004.

SILVA ALVES, Jeferson da. Imperativo: uma análise das variáveis sociais na língua falada de Salvador. Revista Philologus, ano 15, n. 44. Rio de Janeiro: CiFEFiL, maio/ago., 2009, p. 89-105.

TASCA, Maria. A lateral em coda silábica no sul do Brasil. Porto Alegre: PUC-RS, 1999. Tese de doutorado.

THUN, Harald. A dialetologia pluridimensional no Rio da Prata. In: ZILLES, Ana M. Stahl (org.). Estudos de variação lingüística no Brasil e Cone Sul. Porto Alegre: Editora da UFRG, 2005. 